\title{
EL ENDECASÍLABO SÁFICO HORACIANO, MODELO DEL ENDECASÍLABO SILABO-ACENTUAL
}

\author{
Por \\ Miguel Ángel Márquez Guerrero
}

\section{Introducción}

$\mathrm{N}$

AVARRO Tomás ${ }^{1}$ y Baehr ${ }^{2}$ aceptaron la teoría de Menéndez Pelayo según la cual el endecasílabo sáfico romance se habría originado de la realización silabo-acentual del endecasílabo sáfico clásico durante la Edad Media. Es decir, el endecasílabo greco-latino se habría realizado como un verso silabo-acentual, naturalmente por la pérdida de la cantidad de la vocales en la evolución del latín. Esta hipótesis, se fundamenta en la teoría general de la métrica clásica, que considera definitivamente establecida la naturaleza silabo-cuantitativa del endecasílabo sáfico greco-latino, como todos los demás versos eolios. Un ejemplo ilustre nos lo proporciona Safo en su famoso fragmento 31 (Sapph. Fr. 31):

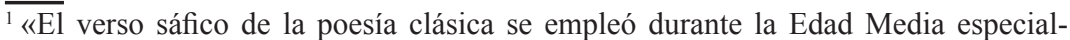
mente en composiciones de carácter religioso. Otro verso de medida semejante, el senario yámbico, alternaba con el sáfico en la misma clase de asuntos. El primero es considerado como base del endecasílabo romance acentuado en cuarta y octava: 'Como epitafio de la ninfa bella', Garcilaso, Égloga III, 239; al segundo se le señala como modelo de la variedad acentuada en sexta: 'Que la curiosidad del elocuente', Ibid., 48» (Navarro Tomás, 1983: 196).

${ }^{2}$ «La necesidad de esta reglamentación severa [del endecasílabo sáfico] se da porque este tipo de endecasílabo intenta imitar el pretendido verso sáfico clásico, que en realidad, por su ritmo, es el latino-medieval» (Baehr,1981: 140). Y en nota,

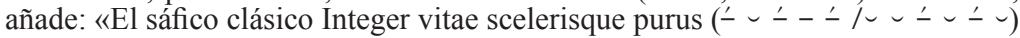
se reprodujo en la baja latinidad como ínteger vítae scelerísque púrus (óoo óo/oo óo óo) conforme a la prosodia natural» (Baehr, 1981: 140 n. 112). 


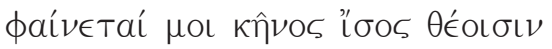

El esquema silabo-cuantitativo del endecasílabo sáfico griego

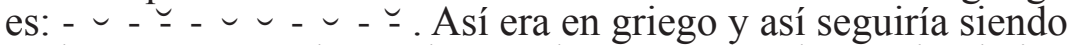
en latín, como podemos leer en los manuales de métrica latina más frecuentemente utilizados (Ceccarelli, 1999). Encontramos en la obra de Catulo la primera aparición del endecasílabo sáfico latino, precisamente en una imitatio de Safo (Cat. 51):

Ille mi par esse deo videtur,

Sin embargo, hay que advertir, que la evolución del sistema cuantitativo al sistema acentual no se realiza simplemente cambiando los ictus por acentos, como parece desprenderse de las palabras de Baehr, práctica a la que nos tienen acostumbrados los distintas tentativas de aclimatación de los versos cuantitativos en la poesía española, a la manera de Rubén Darío ("Salutación del optimista", Cantos de vida y esperanza): «Ínclitas razas ubérrimas, sangre de Hispania fecunda». El proceso es diferente, según advirtió ya Luque Moreno:

Mas lo que en realidad se nota en la mayoría de los casos es la constitución de un ritmo acentual a partir de los acentos de palabra, pero no colocándolos intencionalmente en los lugares del ictus, sino en aquellas sílabas que comúnmente eran acentuadas en el verso cuantitativo (Luque Moreno, 1978: 13).

Así Norberg (1958: 95ss.) analiza poemas del siglo XI escritos en estrofas sáficas, como el siguiente:

Terra marique victor honorande,

Caesar Auguste Hludowice, Christi

Dogmate clarus, decus aevi nostri

Spes quoque regni,

En esos versos, por ejemplo, en el primero, el sistema cuantitativo no se cumple ( _ _ _ _ _ _ _ _ - $)$ ), sino que se sigue una de las series acentuales establecidas a partir de Horacio, con acentos en $1^{\mathrm{a}}, 4^{\mathrm{a}}, 6^{\mathrm{a}}, \mathrm{y} 10^{\mathrm{a}}$ sílabas. 
En resumen, en la poesía arcaica griega nos encontramos por primera vez con el endecasílabo, verso de once sílabas con un patrón cuantitativo muy claro, en el que los ictus determinan el

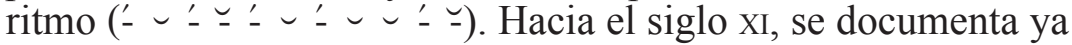
la existencia en latín de endecasílabos sáficos silabo-acentuales, en los que el cómputo sílabico se acompaña de un ritmo acentual rigurosamente establecido, con acentos en $1^{\mathrm{a}}, 4^{\mathrm{a}}, 6^{\mathrm{a}}$ y/u $8^{\mathrm{a}}$, y $10^{\mathrm{a}}$ sílabas, abandonando el esquema cuantitativo.

\section{Método y objetivos}

Aceptando esos presupuestos de la teoría general, debería investigarse el proceso que lleva desde al endecasílabo de su original naturaleza silabo-cuantitativa a su constitución como verso silabo-acentual en la poesía latina del medioevo. El método aparentemente lógico nos llevaría a releer con atención los poemas latino-medievales escritos en estrofa sáfica, para buscar el debilitamiento progresivo del patrón cuantitativo y la aparición del patrón acentual en algún momento de la Alta Edad Media.

Sin embargo, cabe cuestionar la teoría generalmente aceptada, como hizo cierta crítica minoritaria desde el siglo XIX. Podríamos replantearnos el ritmo funcional de los endecasílabos sáficos latinos en época ausgústea y post-augústea. Se comprueba con sorpresa que las estrofas sáficas horacianas presentan un patrón acentual indiscutible, al lado del esquema cuantitativo conocido, que se enseña en el ámbito académico de la filología clásica. Este fenómeno acentual, silencionado o comentado con sordina, afecta a todos los endecasílabos sáficos horacianos; véase, por ejemplo, los primeros que aparecen en las Odas (Hor. Carm. 1.2.1-8):

Iam satis terris nivis atque dirae grandinis misit Pater et rubente dextera sacras iaculatus arces terruit urbem, terruit gentis, grave ne rediret saeculum Pyrrhae nova monstra questae, omne cum Proteus pecus egit altos visere montis 
Todos los versos responden a las expectativas silabo-cuantitativas, pero además se observa un esquema acentual con variedades: acentos en $1^{\mathrm{a}}, 4^{\mathrm{a}}, 6^{\mathrm{a}}$ y $10^{\mathrm{a}}$ sílabas para los versos $1^{\mathrm{o}}$ y $2^{\mathrm{o}}$; acentos en $1^{\mathrm{a}}, 4^{\mathrm{a}}, 8^{\mathrm{a}}$ y $10^{\mathrm{a}}$ sílabas para el verso $3^{\mathrm{o}}$. En el ámbito de la filología clásica, este fenómeno es conocido. La bibliografía secundaria documenta que, desde finales del siglo XIX, se había apuntado la posibilidad de que el acento jugara algún tipo de papel rítmico en los endecasílabos sáficos horacianos. Sin embargo, la teoría aceptada durante todo el siglo xx postula que esa regularidad acentual es secundaria al esquema cuantitativo y las reglas de acentuación de la palabra latina, e irrelevante para el establecimiento del ritmo. En este sentido, los trabajos de Heinze (1918), Seel y Pohlmann (1959) y Moreno Luque $(1978)^{3}$ parecen haber refutado las teorías acentuales de finales del siglo XIX y principios del xx, y haber descartado cualquier posibilidad de una función rítmica real del acento en el verso sáfico de Horacio.

Ahora bien, para la teoría métrica no deja de ser sorprendente el hecho de que exista un patrón acentual tan riguroso en los versos sáficos horacianos. Igualmente significativo resulta comprobar que, en ese esquema, el verso sáfico de Horacio presenta dos variedades acentuales: uno de los acentos alterna entre la $6^{\mathrm{a}}$ y la $8^{\mathrm{a}}$ sílabas, como demuestran los versos $6^{\circ}$ y $7^{\circ}$ de la oda antes citada ${ }^{4}$.

En resumen, mis objetivos son cuatro:

a) Mostrar que, al margen de la voluntad del poeta, el endecasílabo sáfico horaciano desde su origen fue recibido por la mayoría de público romano como un verso silabo-acentual, aunque procediera de un verso silabo-cuantitativo, y el esquema de largas y breves aparentemente siguiera cumpliendo una función rítmica para Horacio y el círculo romano de alta cultura griega.

\footnotetext{
${ }^{3}$ Cabe destacar, entre las obras dedicadas al tema que abordamos, la tesis de Luque Moreno (1978): Evolución acentual de los versos eólicos en latín, que incluye una revisión bibliográfica exhaustiva hasta el momento de su publicación.

${ }^{4}$ Pueden verse los porcentajes relativos en la Tabla III.
} 
b) El endecasílabo romance tendría su raíz última en el ese endecasílabo horaciano, con un eslabón intermedio en la poesía latina medieval ${ }^{5}$; además, el endecasílabo sáfico horaciano no sólo sería el modelo para el endecasílabo romance con acentos en $4^{\mathrm{a}}$ y $8^{\mathrm{a}}$ sílabas sino también para el que va acentuado en $4^{\mathrm{a}}$ y $6^{\mathrm{a}}$ sílabas $^{6}$.

c) Mientras que en los tres primeros libros de las Odas, el endecasílabo presenta una cesura fija tras la $5^{\mathrm{a}}$, en el libro cuarto, Horacio alterna este tipo de endecasílabo con otro tipo que presenta cesura tras la $6^{\mathrm{a}}$ sílaba. Como consecuencia, se generan dos patrones acentuales: $1^{\mathrm{a}}, 4^{\mathrm{a}}, 6^{\mathrm{a}} / 8^{\mathrm{a}}$, y $10^{\mathrm{a}}$ sílabas, y $1^{\mathrm{a}}, 5^{\mathrm{a}}, 7^{\mathrm{a}} / 8^{\mathrm{a}}$ y $10^{a}$ sílabas, cuya afinidad y disonancia rítmica nos plantearemos; por último:

d) Nos cuestionaremos por qué razón rítmica la tradición poética que continuó, desde Séneca en adelante, el endecasílabo sáfico horaciano abandonó el esquema con cesura tras la $6^{\mathrm{a}}$ sílaba y acentos en $1^{\mathrm{a}}, 5^{\mathrm{a}}, 7^{\mathrm{a}} / 8^{\mathrm{a}}$ y $10^{\mathrm{a}}$ sílabas.

\section{El endecasílabo silabo-cuantitativo griego}

En la tradición occidental, el verso con número fijo de once sílabas aparece por primera vez en la poesía arcaica griega. Alceo y Safo, representantes de la lírica monódica, utilizan unos endecasílabos de naturaleza silabo-cuantitativa. El endecasílabo sáfico, que normalmente aparece en la estrofa sáfica (tres endecasílabos y un adonio), presenta el esquema que hemos visto antes. Veamos el poema completo de Safo (Sapph. Fr. 31)

${ }^{5}$ La función intermedia de la poesía latina medieval en la métrica es coherente con la tesis demostrada por Curtius en su Literatura europea y Edad Media latina para tanto otros aspectos literarios.

${ }^{6}$ Alcanzar este tercer objetivo reforzaría la tesis de Navarro Tomás de que el acento relevante para clasificar un endecasílabo español como sáfico es el acento en $4^{\mathrm{a}}$ sílaba, indenpendiente de que el siguiente acento recaiga en la $6^{\mathrm{a}}$ o en la $8^{\mathrm{a}}$ sílaba: "Sáfico. Tres sílabas en anacrusis. Tiempo marcada en la sílaba cuarta; asiento secundario en sexta u octava" (Navarro Tomás, 1983: 199). Como ejemplo de sáfico con acento en $4^{\mathrm{a}}$ y $6^{\mathrm{a}}$ sílabas, Navarro Tomás cita el siguien endecasílabo de Fray Luis de León: "La providencia tiene aprisionada".

7 En el margen derecho, se señala qué sílabas son las acentuadas en el poema de Safo. 


\begin{tabular}{|c|c|}
\hline & \\
\hline 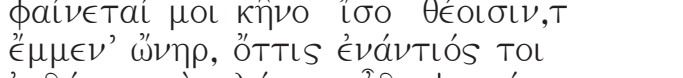 & $1,3,5,8,(10)$ \\
\hline as úmakoúel & \\
\hline 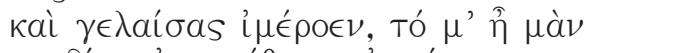 & $53,6,10$ \\
\hline . & \\
\hline 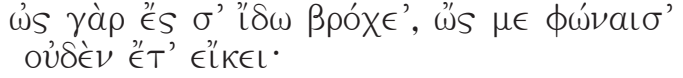 & $4,6,8,10$ \\
\hline 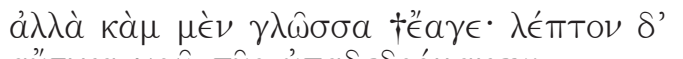 & $2,5,7,10$ \\
\hline & $101,4,5,9$ \\
\hline 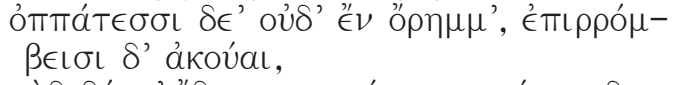 & $2,7,11$ \\
\hline 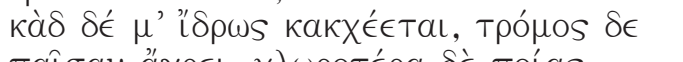 & \\
\hline 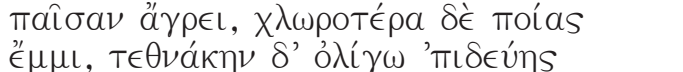 & \\
\hline 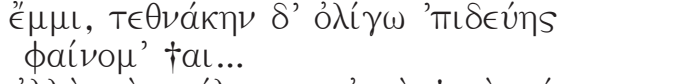 & $151,4,7,1$ \\
\hline & \\
\hline
\end{tabular}

Juzgo dichoso como un dios al hombre que está sentado frente a ti y escucha el dulce arrullo que, al hablar, despiertas con tus palabras y con tu risa encantadora; tiene mi corazón estremecido, porque si yo te miro sólo un breve instante, quedo sin voz: duerme mi lengua, por mi cuerpo corre un tenue fuego, de mis ojos huye toda visión, con mis oídos oigo sólo un zumbido. Un sudor frío me recubre; tiemblo, estoy a punto de morir, se tiñe pronto mi piel de palidez verdosa como la hierba.

Todo tendrá que soportarse, porque... ${ }^{8}$

Es evidente que en los líricos griegos, el endecasílabo sáfico

$\overline{{ }^{8} \text { La }}$ traducción es de E. Torre (1998). 
es un verso al mismo tiempo silábico (estricto cómputo de once sílabas) y cuantitativo (estricta observación del esquema de cantidad, con la $4^{\mathrm{a}}$ sílaba anceps; por ejemplo, larga en el verso $1^{\circ}$, pero breve en el $5^{\circ}$ ). Por otra parte, el acento no juega ningún papel métrico. No es posible establecer ningún patrón acentual en los versos de Safo o de Alceo.

\section{La imitación de Catulo: Cat. 11 y 51}

Catulo imitó el poema 31 de Safo y, en esa imitación, utilizó la estrofa sáfica del original (Cat. 51), estrofa que aparece sólo en otro de sus poemas (Cat. 11). Leamos las primeras estrofas de Cat. 51, señalando el lugar de los acentos:
Ille mi par esse deo videtur, ille, si fas est, superare divos, qui sedens adversus identidem te spectat et audit.
dulce ridentem, misero quod omnes eripit sensus mihi: nam simul te, Lesbia, aspexi, nihil est super mi $<$ vocis in ore; $>$
$1,4,7,10$
$1,4,8,10$
$2,5,8,(11)$
$1,4,6,10$
$1,4,6,9,(11)$
$1,4,6,11$
Parece un dios aquél -y más incluso, si lo permiten, que los mismos dioses- que están sentado frente a ti y escucha y te contempla cuando sonríes con dulzor, robando todo el sentido de mi pobre alma; pues, si te miro, Lesbia, ya no tengo $<$ voz en la boca, $>^{9}$

Señalemos ahora los rasgos más relevantes de estas estrofas, que se diferencian tanto de las estrofas sáficas de Horacio como se asemejan a las de Safo y Alceo:

1) La $4^{\mathrm{a}}$ sílaba puede ser breve o larga, como en el sáfico griego.

2) No hay cesura fija tras la $5^{a}$ sílaba.

3) Se permiten monosílabos al principio, al final y junto a cesura.

${ }^{9}$ La traducción es de E. Torre (1998). 
4) No hay regularidad acentual.

Catulo, por tanto, compone un verso que, como el griego, sigue siendo silabo-cuantitativo, sin que se observe el establecimiento de un patrón acentual.

\section{La primera época de la adaptación horaciana: Horacio Carm. I-III}

Horacio quiso adaptar a la lengua y literatura romana el género de la lírica griega, como había hecho Virgilio con la bucólica, la épica didáctica y la épica heroica ${ }^{10}$. Se supone que a partir del año 30 a.C. compuso sus primeras odas; pero la publicación de los tres primeros libros de Odas en el año 23 a.C. es el momento decisivo de este proceso. Veamos, como ejemplo, Hor. Carm. 2.10, traducida por E. Torre (1998):

Rectius vives, Licini, neque altum semper urgendo neque, dum procellas cautus horrescis, nimium premendo

litus iniquum.

auream quisquis mediocritatem

diligit, tutus caret obsolet

sordibus tecti, caret invidenda

sobrius aula.

saepius ventis agitatur ingens

pinus et celsae graviore casu

decidunt turres feriuntque summos

fulgura montis.

sperat infestis, metuit secundis

alteram sortem bene praeparatum

pectus: informis hiemes reducit

Iuppiter, idem

submovet; non, si male nunc, et olim

sic erit: quondam cithara tacentem

suscitat Musam neque semper arcum tendit Apollo.

rebus angustis animosus atque

$1,4,6,10$
$1,4,6,10$
$1,4,6,10$

$5 \quad 1,4,(6 / 8), 10$

$1,4,6,10$

$1,4,6,10$

$1,4,8,10$
$10 \quad 4,8,10$
$1,4,8,10$

$1,4,6,10$

$1,4,6,10$

$15 \quad 1,4,6,10$

$$
\begin{array}{r}
1,4,6,8,10 \\
1,4,6,10 \\
1,4,8,10
\end{array}
$$

20

$1,4,8,10$

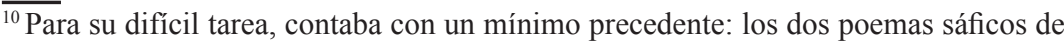
Catulo. 
fortis adpare, sapienter idem

$1,4,8,10$

contrahes vento nimium secundo

$1,4,6,10$

turgida vela.

Mejor, Licinio, vivirás, ni siempre

buscando el seno de la mar, ni mientras

temes sus olas, demasiado amando

costas abruptas.

Quien la dorada medianía quiere

vive apartado de ruinoso techo,

$\mathrm{y}$ de palacios envidiados huye,

sobrio y seguro.

Con gran frecuencia el orgulloso pino

es por los vientos azotado, y torres

inmensas caen, y los rayos hieren

5

montes altísimos.

El corazón disciplinado espera

de adversidad, y de fortuna teme,

suerte distinta; que aunque crudo invierno

Júpiter trajo,

Él se lo lleva. No es igual mañana

que ahora. Sólo alguna vez la cítara

Musas despierta, que no siempre el arco ténsalo Apolo.

En los agobios animoso muéstrate, y sabiamente las hinchadas velas recoge, cuando demasiado sople próspero viento ${ }^{11}$.

En esta primera fase de la aclimatación horaciana del verso sáfico, se han señalado ciertas innovaciones con respecto al sáfico griego y al precedente de Catulo:

a) Esquema riguroso de cantidades (frente a las resoluciones griegas);

b) $4^{\mathrm{a}}$ sílaba siempre larga;

c) Cesura tras la $5^{\text {a }}$ casi universal.

d) Evitación de monosílabos junto a la cesura.

e) Regularidad acentual extraordinaria; para los estudiosos de la métrica clásica, la acentuación regular de esos versos con cesura tras la $5^{\mathrm{a}}$ sílaba sería: $1^{\mathrm{a}}, 4^{\mathrm{a}}, 6^{\mathrm{a}}, 8^{\mathrm{a}}$, y $10^{\mathrm{a}}$. Nosotros observamos a primera vista que no es tan sencilla la acentuación

${ }^{11}$ La traducción es de E. Torre (1998). 
regular: alternancia $1^{\mathrm{a}}, 4^{\mathrm{a}}, 6^{\mathrm{a}}$, y $10^{\mathrm{a}}$ sílabas frente $1^{\mathrm{a}}, 4^{\mathrm{a}}, 8^{\mathrm{a}}$, y $10^{\mathrm{a}}$ sílabas; acentos en $2^{\mathrm{a}}$, etc.

\section{Datos e interpretaciones}

Los hechos son indiscutibles, y es la interpretación de esos hechos lo que puede ser tema de debate. Nadie duda de la universalidad de la cesura tras la $5^{\text {a }}$, la evitación de monosílabos junto a la cesura, o la regularidad acentual. Luque Moreno ha sintetizado el estado de la cuestión:

La gran dificultad, pues, está en dilucidar definitivamente cuál es el término causa y cuál es el término efecto en esta relación, que, por otra parte, parece presentarse como una relación causal. Las 'innovaciones' en la métrica eólica de Horacio, ¿se deben a que el poeta quiere que el acento funcione como elemento rítmico [...]? Por el contrario, el papel rítmico del acento, ¿es sólo aparente, siendo en realidad mera consecuencia involuntaria de unas transformaciones que nada tienen que ver con la acentuación?" (Moreno Luque, 1978: 22).

Sobre los datos antes apuntados, surgieron a finales del siglo XIX teorías que postulaban un ritmo acentual en el sáfico horaciano. Uno de los críticos que defendieron el surgimiento de una superestructura acentual sobre el esquema cuantitativo fue Eickhoffs (1895); en palabras de Luque Moreno:

Eickhoffs concibe el sáfico horaciano como la superposición de una doble estructura rítmica: por una parte Horacio toma del griego la estructura cuantitativa y por otra introduce una estructura acentual que produce algunas alteraciones en la anterior y la reduce a segundo término (Luque Moreno, 1978: 21).

Sin embargo, la teoría general, ha convertido en tabú el problema de la fijación de los acentos en la oda sáfica horaciana. Desde Heinze y Leumann parece vedada cualquier investigación que se base en los acentos del endecasílabo sáfico. Seel y Pohlmann aparentemente asentaron el golpe definitivo a las teorías acentuales, cuando descartaron cualquier intervención de los acentos en la tipología verbal o la métrica verbal del sáfico 
horaciano. Las conclusiones de Luque Moreno (1978: 424-425), como denominador común de todas las teorías aceptadas son las siguientes:

1) En todo los versos eólicos latinos de época clásica el acento no es una base del ritmo.

2) Dada la isosilabia y la fijeza del esquema cuantitativo, se producen casi automáticamente en todos ellos una serie de efectos acentuales, que resultan especialmente intensos en aquellos versos de menos de ocho sílabas o en los cola de semejante extensión determinados por la cesura (hemistiquios del endecasílabo sáfico).

3) Estos efectos acentuales han servido para recalcar y solidificar unas determinadas formas de estructurar el verso a las que ya se tendía por diversos motivos desde muchos antes.

4) Dichos efectos de acentuación no parecen haber pasado desapercibidos a los versificadores, los cuales, incluido el propio Horacio, parecen haber insistido en ellos.

La teoría de que en Horacio sigue siendo un verso exclusivamente silabo-cuantitativo se sustenta en la idea de que la fijación de los acentos es un fenómeno secundario motivado por el esquema cuantitativo, la cesura tras la $5^{\mathrm{a}}$ y por las reglas que rigen el acento en la lengua latina. Para que funcione esta teoría, además hay que aceptar que otros dos fenómenos son previos e independientes a la fijación de los acentos:

a) la evitación de monosílabos en inicio y final de verso y junto a la cesura;

b) la realización de la $4^{\mathrm{a}}$ sílaba siempre como larga.

Este modelo se sostiene además explicando por qué motivo introduce Horacio todas estas innovaciones: regularizar una fuerte tendencia que era griega tanto como latina (cesura tras la $5^{\mathrm{a}}$ y $4^{\mathrm{a}}$ siempre larga), teoría enunciada en 1918 por R. Heinze, y que no goza de una aceptación universal. El objetivo sería evitar la impresión de ritmo trocaico al comienzo de verso, pues el ritmo trocaico se relacionaba con las canciones populares romanas.

En cualquier caso, la existencia real del ritmo de los acentos en los endecasílabos sáficos horacianos debe ser asumida incluso 
por aquellos que defienden la teoría de Heinze de que Horacio sólo estaba regularizando una fuerte tendencia que es tan griega como romana. Y así concluye Wilkinson:

We may take it, then, that Horace did not intend to create the rhythm. But the fact remains that the over whelming majority of Sapphic hendecsyllabes in the Three Books have it" (Wilkinson, 1940: 133).

\section{Comparación con el hexámetro}

Moreno Luque entiende que, en el endecasílabo sáfico de Horacio, ocurre un fenómeno paralelo a lo que ocurre con el final del hexámetro. El hexámetro griego es puramente cuantitativo y los acentos no cumplen ninguna función métrica en el verso épico. Sin embargo, en la adaptación que del hexámetro al latín, desde la última cesura hasta el final, los acentos se superponen a los ictus. Podemos comparar el principio de la Ilíada y el de la Eneida (Il. 1.1-10, Verg. A. 1.1-7) ${ }^{12}$ :

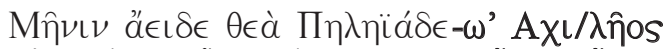

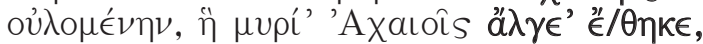

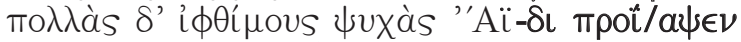

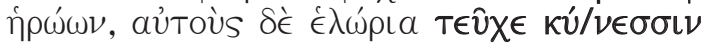

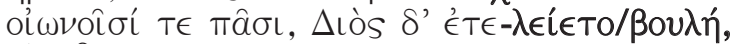

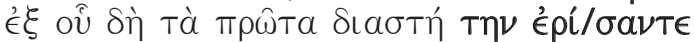

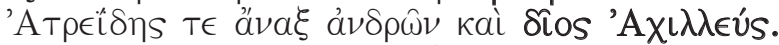

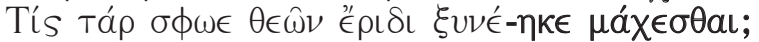

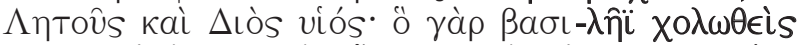

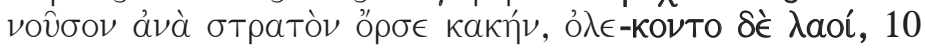

Arma uirumque cano, Troiae qui prímus ab óris Italiam fato profugus Lauíniaque uénit litora, multum ille et terris iactátus et álto ui superum, saeuae memorem Iunónis ob íram, multa quoque et bello passus, dum cónderet úrbem 5 inferretque deos Latio; genus únde Latínum Albanique patres atque altae móenia Rómae.

$\overline{{ }^{12} \mathrm{Si}}$ volvemos ahora a la estrofa sáfica de Hor. Carm. 2.10 podremos comprobar también este fenómeno en el adonio final. 
Musa, mihi causas memora, quo númine láeso quidue dolens regina deum tot uóluere cásus insignem pietate uirum, tot adíre labóres

En la Eneida, el ritmo dactílico del final del hexámetro se refuerza con el esquema acentual de adire labóres.

\section{Ritmos concordantes y ritmos discordantes}

Ahora bien, nótese que hay una diferencia esencial en la aparición del acento fijo en el hexámetro y en el endecasílabo sáfico. En el hexámetro de Virgilio, hay una superposición de ritmo cuantitativo y ritmo acentual, al coincidir ictus y acentos en el final de verso; así pues, ambos ritmos no se "contradicen" sino que cooperan y el verso cuantitativo presenta un esquema acentual fijo en su dos últimos pies. Por el contrario, en el endecasílabo sáfico horaciano, el ritmo acentual no se "superpone" al ritmo cuantitativo. En realidad ambos ritmos entran en fuerte contradicción y, en lugar de "cooperar" establecen ritmos distintos, como señaló Eickhoffs (1895).

Esta contradicción entre los ritmos cuantitativo y acentual del endecasílabo sáfico horaciano, debe resolverse con la predominancia de uno de los dos, que sería el que fijaría verdaderamente el ritmo del verso. No pueden funcionar simultáneamente ambos ritmos: creo que en estas condiciones, habría que cuestionar la teoría general, y tener en cuenta cómo fue recibido ese verso por el público romano coétaneo y por los poetas posteriores que siguieron la tradición horaciana, por ejemplo, Séneca y Ausonio, independientemente de cuál fuera la voluntad innovadora de Horacio.

La crítica ya ha señalado la posibilidad de que los endecasílabos silabo-cuantitativos de Horacio, fueran recibidos como endecasílabos silabo-acentuales por el público de la época. Luque Moreno sugiere que Horacio se dio cuenta que el difícil juego de ictus y acentos no era bien comprendido por el público romano, «que tendería a dejarse llevar por el ritmo más fácil de los acentos prosaicos de las palabras» (Luque Moreno, 1978: 38). 


\section{La segunda época de la adaptación horaciana}

Horacio había creído ver en los tres primeros libros de sus odas la cima de su arte poético. Pero fue un fracaso rotundo de público. Desilusionado, el poeta abandonó la alta poesía y volvió a los sermones filosofantes. Pasaron seis años, hasta que Augusto le encargó un himno para la fiesta del año 17 a.C. y compuso el Carmen saeculare en estrofas sáficas, para ser cantado por un coro de jóvenes (virgines lectas puerosque castos, verso $6^{\circ}$ ). A partir de ese momento escribe las odas del libro IV, entre las que se encuentran tres sáficas $(4.2,4.6$, y 4.11 , probablemente escritas entre los años 17 y 15 a.C.). En esta segunda fase de adaptación de la estrofa sáfica, nos encontramos una diferencia fundamental con respecto a la primera fase, representada por los tres primeros libros de las Odas: la presencia significativa de versos con cesura tras la $6^{\mathrm{a}}$ sílaba y un esquema acentual totalmente distinto a los versos que presentan cesura tras la $5^{\mathrm{a}}$. Veamos, como ejemplo, Hor. Carm. 4.11:

Est mihi nonum superantis annum

plenus Albani cadus, est in horto,

Phylli, nectendis apium coronis,

est hederae vis

multa, qua crinis religata fulges;

ridet argento domus, ara castis

vincta verbenis avet immolato

spargier agno;

cuncta festinat manus, huc et illuc

cursitant mixtae pueris puellae,

sordidum flammae trepidant rotantes

vertice fumum.

ut tamen noris, quibus advoceris gaudiis, Idus tibi sunt agendae, qui dies mensem Veneris marinae

findit Aprilem,

iure sollemnis mihi sanctiorque

paene natali proprio, quod ex hac

luce Maecenas meus adfluentis

ordinat annos.

Telephum, quem tu petis, occupavit 
non tuae sortis iuvenem puella dives et lasciva tenetque grata compede vinctum.

terret ambustus Phaethon avaras

$$
1,5,8,10
$$

spes et exemplum grave praebet ales

Pegasus terrenum equitem gravatus

Bellerophontem, semper ut te digna sequare et ultra quam licet sperare nefas putando disparem vites. age iam, meorum finis amorum non enim posthac alia calebo femina, condisce modos, amanda voce quos reddas: minuentur atrae carmine curae.

Guardo una tina llena de un albano envejecido y en mi huerto hay, Filis, para trenzar coronas apio

y mucha yedra

que dé esplendor a tu peinado. Dentro 5 ríe la plata, y el altar ceñido

por casta fronda anhela de un cordero sangre inmolada.

Todas las manos se apresuran; corren esclavas junto a esclavos por doquier.

Tiemblan las llamas y un grasiento humo gira y asciende.

Conoce a qué celebración te invito:

debemos festejar los idus, cuando

se escinde en dos el mes de la marina

Venus, Abril,

Día solemne y para mí más sacro que mi propio natal, porque con esa luz mi amigo Mecenas de los años ordena el curso.

Ha domeñado a Télefo (lo quieres aunque no sea de tu clase) otra, rica y alegre, y lo tiene preso grata cadena.

Faetón quemado aterra al ambicioso, 
y ejemplo grave Pégaso el alado da al terrenal jinete que lo grava, Belerofonte.

Siempre persigue lo adecuado a ti.

Piensa nefasto lo que está prohibido

y lo dispar evita. Tú, final

de mis amores

(otra mujer no habrá que me enardezca),

aprende ritmos y que tu querida

voz los ensaye; el canto amenguará

negras las cuitas. ${ }^{13}$

La proporción de versos con cesura tras la sexta sílaba es, en el libro IV de las Odas, muy significativa: el 26\%. Más de una cuarta parte de los versos tienen, pues, cesura tras $6^{\mathrm{a}}$ sílaba. La acentuación cambia también radicalmente. La cesura tras $6^{\mathrm{a}}$ sílaba se acompaña con dos acentuaciones distintas: acentos en $1^{\mathrm{a}}, 5^{\mathrm{a}}, 7^{\mathrm{a}}$, y $10^{\mathrm{a}}$ sílabas (como en los versos 27,30 y 34 de la $O d a$ 4.11) o en $1^{\mathrm{a}}, 5^{\mathrm{a}}, 8^{\mathrm{a}}$, y $10^{\mathrm{a}}$ sílabas (como en los versos 23 y 29 de la misma $O d a$, variantes que aparecen con la siguiente proporción: $75 \%$ y $25 \%$ respectivamente.

Quizá Horacio intentó introducir un nuevo esquema acentual, para evitar la excesiva monotonía de los numerosos endecasílabos sáficos con acento en $1^{\mathrm{a}}, 4^{\mathrm{a}}, 6^{\mathrm{a}} / 8^{\mathrm{a}}$, y $10^{\mathrm{a}}$ sílabas. Por eso, de forma significativa se apartó de la regla por él establecida sobre la fuerte tendencia anterior de la cesura universal tras la $5^{\mathrm{a}}$. La cesura tras la $6^{\mathrm{a}}$ sílaba le facilitó el nuevo esquema acentual.

Si la teoría general (la encabezada por Heinze) postulaba que la regularización de la cesura tras la $5^{\mathrm{a}}$ sílaba era un fortalecimiento de una fuerte tendencia anterior, que afecta tanto al endecasílabo sáfico griego como al latino, frente a la nueva época y la nueva cesura apenas nada puede argumentarse. De esta manera, Wilkinson (1940), siguiendo a Heinze, se dio por satisfecho con la hipóstesis de que el oído de Horacio pudo cambiar con respecto a los tres primeros libros de Odas. Debemos anotar que en esa época Horacio estaba a punto de cumplir los cincuenta años.

$\overline{{ }^{13} \mathrm{La}}$ traducción es mía. 


\section{El acento y la tipología verbal}

Las innovaciones de la segunda época (cesura tras la $6^{\mathrm{a}}$ y acentuación en $1^{\mathrm{a}}, 5^{\mathrm{a}}, 7 / 8^{\mathrm{a}}$, y $10^{\mathrm{a}}$ sílabas) no tuvieron continuación en la poesía latina posterior. Séneca, Ausonio y todos los demás poetas que utilizaron la estrofa sáfica compusieron sus endecasílabos con el esquema que hemos visto a propósito de los tres primeros libros de Odas.

Sin embargo, esos versos con cesura tras la $6^{\mathrm{a}}$ sílaba de la segunda época nos ofrecen un argumento importante para postular el carácter silabo-acentual del endecasílabo sáfico horaciano. La cesura en el endecasílabo latino genera dos hemistiquios, uno de cinco sílabas y otro de seis; su orden se intercambia según la cesura vaya tras la $5^{\text {a }}$ o la $6^{\text {a }}$ sílaba. Luque Moreno nos advierte que el tanto por ciento de cada tipología verbal debería ser similar en los dos hemistiquios de cinco sílabas (el $1^{\circ}$ en el verso con cesura tras la $5^{\mathrm{a}}$ sílaba, y el $2^{\circ}$ en el verso con cesura tras las $6^{a}$ sílaba) y en los dos hemistiquios de seis sílabas:

habría que esperar que en el segundo hemistiquio del sáfico con cesura en sexta sílaba la frecuencia de cada tipología fuese la misma que en el primer hemistiquio del sáfico con cesura en quinta $\mathrm{y}$, asimismo, en el primer hemistiquio del sáfico con cesura en sexta ocurriese lo mismo con respecto al segundo hemistiquio del sáfico con cesura en quinta (Luque Moreno, 1978: 61).

Después de dar con la clave metodológica, Luque Moreno se detiene en las distribuciones $3+2$ y $2+3$ que ocurren en los dos hemistiquios de cinco sílabas (el $1^{\mathbf{o}}$ en el verso con cesura tras la $5^{\mathrm{a}}$, y el $2^{\circ}$ en el verso con cesura tras las sexta), y otras similares para llegar a la conclusión de que es la cohesión entre el endecasílabo y el adonio la que lleva a preferir ciertas tipologías verbales. Sin embargo, a Luque Moreno le pasó desapercibida unas diferencias que puede apoyar definitivamente la naturaleza acentual del sáfico horaciano. Veamos las distribuciones más frecuentes en los hemistiquios de seis sílabas: 


\begin{tabular}{|c|c|c|}
\hline Tipología verbal & $2^{\circ}$, con cesura tras $5^{\mathrm{a}}$ & $1^{\circ}$, con cesura tras $6^{\mathrm{a}}$ \\
\hline $3+3$ & 28 & 46 \\
\hline $\mathbf{4 + 2}$ & $\mathbf{2 4}$ & $\mathbf{0}$ \\
\hline $2+1+3$ & 13 & $\mathbf{0}$ \\
\hline $\mathbf{2 + 2 + 2}$ & $\mathbf{1 2}$ & 13 \\
\hline $2+4$ & 11 & 13 \\
\hline
\end{tabular}

¿Por qué se evitan en la primera parte del endecasílabo con cesura tras la $6^{\mathrm{a}}$ sílaba las tipologías $4+2$ y $2+2+2$, tan frecuentes en el segundo hemistiquio del verso con cesura tras la $5^{\mathrm{a}}$ sílaba? No se puede aducir ninguna razón desde las teorías cuantitativas, porque no la hay. Pero veamos qué relación tienen esas dos tipologías con los acentos según intervengan en cada uno de los dos hemistiquios de seis sílabas del endecasílabo sáfico.

En el segundo hemistiquio del sáfico con cesura tras la $5^{\mathrm{a}}$ sílaba, todas las tipologías recogidas en la tabla permiten la acentuación esperada: $6^{\mathrm{a}} \mathrm{y} / \mathrm{u} 8^{\mathrm{a}}$, y $10^{\mathrm{a}}$ sílabas. Ahora bien, en el primer hemistiquio del sáfico con cesura tras la $6^{\mathrm{a}}$ sílaba, las tipologías que Horacio utiliza llevan a la acentuación en $1^{\mathrm{a}}$ y $5^{\mathrm{a}}$ sílabas, y las que evita (es decir, 4+2 y $2+2+2$ ) a la acentuación en $3^{\mathrm{a}}$ y $5^{\mathrm{a}}$ o en $1^{\mathrm{a}}, 3^{\mathrm{a}}$ y $5^{\mathrm{a}}$ sílabas.

\section{La cláusula cuaternaria}

Podemos postular que Horacio no utiliza las tipologías 4+2 y $2+2+2$ en el primer hemistiquio del endecasílabo sáfico con acento tras la $6^{\mathrm{a}}$ sílaba para evitar el acento en $3^{\mathrm{a}}$ sílaba; además la tipología 4+2 impide el esperado acento en $1^{\mathrm{a}}$ sílaba ${ }^{14}$. La evitación del acento en $3^{\mathrm{a}}$ sílaba en el primer hemistiquio de los versos con cesura tras la $6^{\mathrm{a}}$ sílaba debe tener una explicación rítmica. Para explicar el fenómeno debemos volver a comparar el ritmo cuantitativo y el ritmo acentual de las dos variedades de endecasílabos sáficos horacianos.

\footnotetext{
$\overline{14}$ [Las evitadas tipologías con monosílabo tras la cesura. El segundo hemistiquio del endecasílabo sáfico con cesura tras $6^{a}$ puede coincidir con la primera parte del eneasílabo de la estrofa alcaica. En el segundo hemistiquio del sáfico no hallamos las volumetrías $1+4$ o 1+2+2; sin embargo, esas volumetrías son posibles en el eneasílabo de la estrofa alcaica (aproximadamente un 14\%): ab insolenti (2.3.3); te triste lignum (2.13.4)].
} 
El endecasílabo sáfico desde el punto de vista cuantitativo se analiza como un verso con tres secciones (como todos los versos eolios): comienzo, parte central y cadencia (Luque Moreno, 1996). En cuanto al ritmo, se observa una sucesión de ritmo binario $(2,2)$, ternario $(3)$, binario $(2,2)$ :

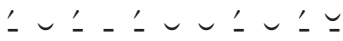

En el esquema anterior, la tilde marca el lugar de los ictus y no el de los acentos. Este análisis confirma la idea generalmente aceptada de que en la métrica cuantitativa alternan los ritmos binarios y ternarios (en diferentes órdenes). Pero desde el punto de vista del ritmo acentual la situación es muy diferente. Si marcamos con la tilde ahora el lugar de los acentos, para el endecasílabo sáfico con cesura tras la $5^{\mathrm{a}}$ sílaba, son posibles los siguientes tres esquemas, según tenga acento en $6^{\mathrm{a}}, 8^{\mathrm{a}}$ o $6^{\mathrm{a}}$ y $8^{\mathrm{a}}$ sílabas:

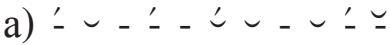
b) $-\cup-1-\cup \cup \div '-$
c) $-\cup-1 \cdot\llcorner\div-\div$

Pasemos ahora al endecasílabo sáfico con cesura tras la $6^{\mathrm{a}}$ sílaba, propio del libro IV de las Odas. Si marcamos los acentos con la tilde, son posibles dos esquemas acentuales:

d) $-\cup \ldots$

e) $-\cup-\ldots$

Podemos preguntarnos si estas cinco modalidades acentuales son reductibles a la alternancia del ritmo binario y el ritmo ternario. Creo que no, porque desde el punto de vista acentual se ha introducido una cláusula cuaternaria, entre los acentos en $6^{\mathrm{a}}$ y $10^{\mathrm{a}}$ sílabas para el esquema a); entre los acentos $4^{\mathrm{a}}$ y $8^{\mathrm{a}}$ sílabas para el esquema $b$ ); y entre $1^{\mathrm{a}}$ y $5^{\mathrm{a}}$ sílaba para los esquemas d) y e). Sólo el esquema c) con acento en $6^{\mathrm{a}}$ y $8^{\mathrm{a}}$ carece de esa claúsula cuaternaria y, en consecuencia, podría analizarse como una secuencia de ritmo binario y ternario. Pero el resto, una mayoría muy cualificada, presenta una cláusula cuaternaria. 


\section{Conclusiones}

1) Recepción del endecasílabo sáfico horaciano como verso silabo-acentual

El análisis de los versos sáficos de Catulo (§ 4) no deja lugar a dudas de que, en su adaptación al latín del endecasílabo griego, el poeta compuso en su lengua un verso silabo-cuantitativo. Sin embargo, en las odas sáficas horacianas, el endecasílabo deja abierta muchas cuestiones. Nuestro objetivo no es tanto saber si Horacio introdujo sus innovaciones en la métrica eólica (de naturaleza silabo-cuantitativa) porque quería que el acento funcionara como elemento rítmico, o si por el contrario Horacio con esas innovaciones no pretendía otorgar ningún papel rítmico al acento y su regularidad sólo fue una consecuencia involuntaria.

Al margen de la voluntad de Horacio, el público romano de la época augústea y los poetas posteriores que consolidaron la tradición del endecasílabo sáfico horaciano (Séneca, Ausonio, Boecio) no pudieron compaginar, en un verso recitado ${ }^{15}$, la contradicción rítmica de ictus y acentos. La regularidad de los acentos en el sáfico horaciano y la pérdida de cantidad (entendemos que un fenómeno secular y tal vez iniciado en época de Augusto) destinaban a la interpretación del endecasílabo sáfico horaciano como un verso silabo-acentual ${ }^{16}$.

\section{2) Modelos para el endecasílabo sáfico romance}

Aunque se negara esta recepción silabo-acentual en época de Horacio e inmediatamente después, nadie cuestionará que, en la Baja Edad Media, no se percibía la cantidad desde hacía muchos siglos: ¿cómo tuvieron que entenderse los versos de Horacio? Necesariamente como versos silabo-acentuales. Si hubo un modelo para el sáfico romance, no hay que buscarlo en los poemas de Alcuino de York o Pedro Abelardo, sino en la recepción de los sáficos de Horacio, Séneca, etc. como versos silabo-acentuales desde época muy temprana.

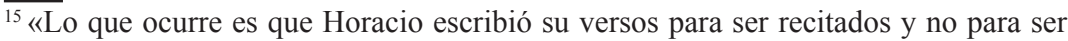
cantados» (Moreno Luque, 1978: 37). Los versos eolios griegos eran cantados.

${ }^{16}$ «Pero a la vez se da cuenta de que este difícil juego entre ictus y acento no debía ser bien comprendido por el pueblo, que tendería en su lectura a dejarse llevar por el ritmo más fácil de los acentos prosarios de las palabras» (Luque, 1978: 38).
} 
El endecasílabo horaciano proporciona el modelo no sólo para los endecasílabos con acento en $1^{\mathrm{a}}, 4^{\mathrm{a}}, 8^{\mathrm{a}}$ y $10^{\mathrm{a}}$ sílabas, sino también para endecasílabos con acento en $1^{\mathrm{a}}, 4^{\mathrm{a}}, 6^{\mathrm{a}}$ y $10^{\mathrm{a}}$ sílabas, cuya evolución en Italia pudo dar lugar a lo que conocemos como endecasílabo común (es decir, con acento en $6^{\mathrm{a}}$ y $10^{\mathrm{a}}$ sílabas).

\section{3) Cláusula cuaternaria}

Creo que desde el punto de vista acentual, podemos establecer la hipótesis de la existencia de una unidad rítmica cuaternaria ${ }^{17}$, junto al ritmo binario y ternario. Esta unidad cuaternaria es común al endecasílabo con cesura tras la $5^{\mathrm{a}}$ sílaba (entre los acentos de $4^{\mathrm{a}}$ y $8^{\mathrm{a}}$, y entre los acentos de $6^{\mathrm{a}}$ y $10^{\mathrm{a}}$ ) y al endecasílabo con cesura tras la $6^{\mathrm{a}}$ sílaba (entre los acentos de $1^{\mathrm{a}}$ y $5^{\mathrm{a}}$ ).

Además, la unidad acentual cuaternaria puede ser la causa de la evitación del acento en $3^{\mathrm{a}}$ sílaba en los endecasílabos con cesura tras la $6^{\mathrm{a}}$ sílaba. Para eludir ese acento que rompería la unidad cuaternaria, se evitan los tipos verbales $4+2$ y $2+2+2$ en el primer hemistiquio del endecasílabo con cesura tras la $6^{a}$ sílaba.

4) La no supervivencia del endecasílabo con cesura tras la $6^{\mathrm{a}}$ sílaba

Séneca y los demás poetas que continuaron la tradición del endecasílabo sáfico fundada por Horacio desecharon el endecasílabo sáfico con cesura tras la $6^{\mathrm{a}}$ sílaba. Desde Séneca a Boecio y en toda la tradición latina medieval, los endecasílabos sáficos presentan un esquema idéntico al verso horaciano con cesura

${ }_{17}$ Esta unidad rítmica cuaternaria que proponemos tiene un antecedente en la teoría métrica de Sinibaldo de Mas. Con la terminología propia, Sinibaldo de Mas habla una segunda sílaba acentuada, una tercera sílaba acentuada, y, esto es lo que nos interesa, una cuarta sílaba acentuada. Este es el sistema que se utiliza para explicar el ritmo del endecasílabo: «Sin embargo, persuadido yo de la existencia de dichas leyes, traté de investigar a fondo la cuestión, y observé que dos terceras sílabas acentuadas seguidas de una cuarta acentuada forman una melodía, como en este verso: En sus cándidos pechos le adormece. Observé igualmente que una cuarta acentuada seguida de una segunda, la hacen también, como en este: Dulce vecino de la verde selva» (Domínguez Caparrós, 2001: 53). No es este el lugar para discutir a fondo las teorías que propuso Sinibaldo de Mas para explicar las consonancias entre las segundas, terceras y cuartas sílabas acentuadas, ideas no siempre asumibles. Baste esta nota para dejar constancia del paralelo entre su cuarta acentuada y la unidad rítmica cuaternaria que proponemos. 
tras la $5^{\mathrm{a}}$ sílaba. ¿Por qué los poetas latinos que seguían la senda iniciada por Horacio no aceptaron su innovación con respecto al esquema universal de los tres primeros libros de las Odas?

Quizá la única razón que podamos aducir es que el endecasílabo con cesura tras la $6^{\circ}$ sílaba (y, por tanto, con acento en $5^{\mathrm{a}}$ sílaba) no armonizaba bien con el endecasílabo con cesura tras la $5^{\mathrm{a}}$ sílaba (y, por tanto, con acento en $4^{\mathrm{a}}$ sílaba). Cabría preguntarse por qué la tradición poética consideró que la combinación de ambos tipos de endecasílabos no "sonaba" bien, si el esquema cuantitativo era idéntico para las dos variedades y sólo se diferenciaban en el lugar de la cesura. La respuesta se halla en que, desde muy temprano, quizá ya desde Séneca, el ritmo prevalente era el acentual y esos dos tipos de endecasílabos, aunque tenían el mismo esquema cuantitativo, disonaban por sus acentos desde el punto de vista de la tradición poética, a pesar de que Horacio pretendió sin continuidad la combinación de los dos tipos basándose en la identidad cuantitativa y en la común unidad acentual cuaternaria.

\section{Bibliografía}

Alonso, Dámaso (1973): "Elogio del endecasílabo", en Obras completas II, Madrid: Gredos, 539-542.

Bloom, H. (2001): El canon occidental, Barcelona: Anagrama.

BoldRINI, S. (1992): La prosodia e la metrica dei Romani, Roma.

Ceccarelli, L. (1999): Prosodia y métrica del latín clásico: con una introducción a la métrica griega, traducción de Rocío Carande, Sevilla: Universidad de Sevilla.

Domínguez CaPARrós, José (1993): Métrica española, Madrid: Síntesis, 152155.

- (2001): Sinibaldo de Mas. Sistema musical de la lengua castellana, Madrid: CSIC.

Eickhoffs, P. (1895) Der horazische Doppelbau der Sapphischen Strophe und seine Geschichte, Wandsbeck.

Fernández-GaLIano, M. (1983): "Un experimento de traducción rítmica horaciana", Bivium. Homenaje a M. C. Díaz y Díaz, Madrid, 81-87.

Heinze, R. (1918) Die lyrischen Verse des Horaz (=1960, Stuttgart).

Hellegouarch, J. (1966): "Observations stylistiques et métriques sur les vers lyriques d'Horace", L'Information Littéraire 18, 66-74. 
Lenchantin de Gubernatis, M. (1934): "I metri eolici della lirica latina", Atheaeum 12, 239-254.

Luque Moreno, J. (1978): Evolución acentual de los versos eólicos en latín, Granada: Universidad de Granada.

- (1996): "Las formas métricas de la lírica horaciana", FlorIlib 7, 187211

Marcos Casquero, M.A. y Oroz Reta, J. (1997): Lírica Latina Medieval II. Poesía religiosa, Madrid: Biblioteca de Autores Cristianos.

McDermott, E. (1981): "Greek and Roman Elements in Horace's Lyric Program", Aufstieg und Niedergang der römischen Welt, II.31.3, 16401672 .

Menéndez Pelayo, M. (1890-1916): Antología de poetas líricos castellanos, Madrid, pp. 161-239.

Navarro TomÁs, TomÁs (1983): Métrica española, Barcelona: Labor.

Norberg, D. (1958): Introduction à l'étude de la versification latine mediéval, Estocolmo.

Pichon, R. (1893): "Les mètres lyriques d'Horace", Revue de Philologie 17, 132-140.

PIGHI, G. B. (1958): I ritmi e i metri della poesia latina, con particulare riguardo all'uso dei Catullo e d'Orazio, Brescia.

Prakken, D. W. (1954): "Feminine caesuras in Horat sapphic stanzas", Classical Philology 49, 102-103.

RodríGuez-PANTOJA, M. (1984): “Apuntes para la versión rítmica de algunas odas horacianas", Actas del II Congreso Andaluz de Estudios Clásicos, I, 307-311.

Seel, O. Y Pohlmann, E. (1959): "Quantität und Wortakzent im horazischen Sapphiker. Ein Beitrag zum Iktus-Problem”, Philologus CIII, 237-280.

Torre, E. (1998) La poesía de Grecia y Roma. Ejemplos y modelos de la cultura literaria moderna, Huelva: Universidad de Huelva.

Torre, Esteban (2000): Métrica española comparada, Sevilla: Universidad de Sevilla.

WiLKInSON, L. P. (1940): "Acentual rhythm in Horatian sapphic", Classical Review 54, 131-ss.

WiLKInSON, L. P. (1951): Horace and his lyric poetry, Cambridge. 